\title{
Clinical Outcomes of Large (>10 mm) Unruptured Posterior Circulation Aneurysms and Their Predictors
}

\author{
Joonho Byun, Wonhyoung Park, Jung Cheol Park, Jae Sung Ahn \\ Department of Neurosurgery, Asan Medical Center, University of Ulsan College of Medicine, Seoul, Korea
}

Objective : The treatment of large aneurysms of the posterior circulation is complicated and remains challenging. We here analyzed our institutional clinical outcomes of large unruptured aneurysms of the posterior circulation.

Methods : This study included 56 patients who presented with a large $(>10 \mathrm{~mm})$ unruptured aneurysm of the posterior circulation between 2002 and 2018.

Results : There were 18 (32.1\%) male and 38 (67.9\%) female patients, with a mean age of 53.4 years. The most common location was the vertebral artery, followed by the basilar tip and posterior cerebral artery. The median follow-up duration was 29 months. Eighteen patients (32.1\%) were treated by transcranial surgery and 38 (67.9\%) were treated by endovascular treatment (EVT). Posttreatment complications occurred in 16 patients $(28.6 \%)$, with there being no significant difference between the transcranial surgery and EVT groups. Complete obliteration was achieved in 30 patients (53.6\%), with there being no statistically significant difference between the transcranial surgery and EVT groups. Recurrence occurred in 17 patients (30.4\%), and the rate of recurrence was higher in the EVT group than in the transcranial surgery group (39.5\% vs. $11.1 \%, p=0.03$ ). Forty-four (84\%) of 56 patients showed a favorable functional outcome. In saccular aneurysm, EVT was negative predictor of worsening of functional status.

Conclusion : Treatment of these aneurysms harbors an inherent high risk of morbidity. No superiority was found between transcranial surgery and EVT in terms of complications and complete obliteration, but transcranial surgery showed a higher treatment durability than EVT.

Key Words : Aneurysm, Large, Unruptured · Surgery · Treatment outcome · Complications · Posterior circulation.

\section{INTRODUCTION}

The treatment of large $(>10 \mathrm{~mm})$ aneurysms of the posterior circulation is very complicated, and both transcranial and endovascular treatment (EVT) remain challenging. Large aneurysms of the posterior circulation frequently incorporate the parent artery and crucial perforators, contain thrombus, and are frequently adherent to critical neural structures ${ }^{2}$. Thus, the post-treatment complication rates of both transcranial surgery and EVT are high for large aneurysms of the posterior circulation $^{2,4)}$, and the risk of rupture for large posterior circulation aneurysms is higher than that for small and anterior circulation aneurysms ${ }^{7}$. Thus, the treatment decision for an 'unruptured' large aneurysm of the posterior circulation is a

- Received : February 4, 2020 •Revised : March 23, 2020 •Accepted : May 12, 2020

- Address for reprints : Wonhyoung Park

Department of Neurosurgery, Asan Medical Center, University of Ulsan College of Medicine, 88 Olympic-ro 43-gil, Songpa-gu, Seoul 05505, Korea Tel : +82-2-3010-1865, Fax : +82-2-476-6738, E-mail : elevenes@gmail.com, ORCID : https://orcid.org/0000-0002-9977-0595

This is an Open Access article distributed under the terms of the Creative Commons Attribution Non-Commercial License (http://creativecommons.org/licenses/by-nc/4.0) which permits unrestricted non-commercial use, distribution, and reproduction in any medium, provided the original work is properly cited. 
very difficult one to make and must consider the patients' minimal symptoms and neurological deficits, the high risk of aneurysmal rupture, and the high post-treatment complication rate.

In this report, we document our institutional post-treatment outcomes of large unruptured aneurysms of the posterior circulation. Furthermore, we analyze the predictors of posttreatment complications and functional outcomes. The sharing of our clinical data should be helpful for decision making on the treatment of an unruptured large aneurysm of the posterior circulation.

\section{MATERIALS AND METHODS}

\section{Patient population}

The study protocol and retrospective review of medical records were approved by the Institutional Review Board of Asan Medical Center (IRB No. 2019-1486). Between 2002 and 2018, a total of 9166 patients with an intracranial aneurysm were treated in our institution. Of these patients, 8397 (91.6\%) had an anterior circulation aneurysm, 769 (8.4\%) had a poste- rior circulation aneurysm, and $103(1.12 \%)$ had a large (>10 $\mathrm{mm})$ aneurysm, with $65(0.7 \%)$ having a large unruptured posterior circulation aneurysm. Patients with a recurrent aneurysm or an aneurysm combined with other vascular disease, including arteriovenous malformation, were excluded. Finally, a total of 56 patients were enrolled in this study (Fig. 1).

The consensus of treatment decision making between transcranial surgery and EVT has not been established. In our institution, decision of treatment modalities for complex aneurysm has been established after discussion with neurosurgeons, neuroradiologist and neuro-interventionist. We have advocate EVT for large posterior circulation aneurysm because of its difficulty of microsurgical accessibility and high morbidity. However, we have preferred transcranial surgery for aneurysm which shows mass effect, contain thrombus, incorporate critical perforators or branches. Also, neurosurgeon's personal preference affects the treatment decision making.

The follow-up examinations included physical examination and measurement of functional outcome at discharge from hospital and at 1, 3, 6, and 12 months after treatment. Computed tomography angiography was obtained at were obtained at 1 or 3 months, 1 year after treatment, and then every 1 or 2

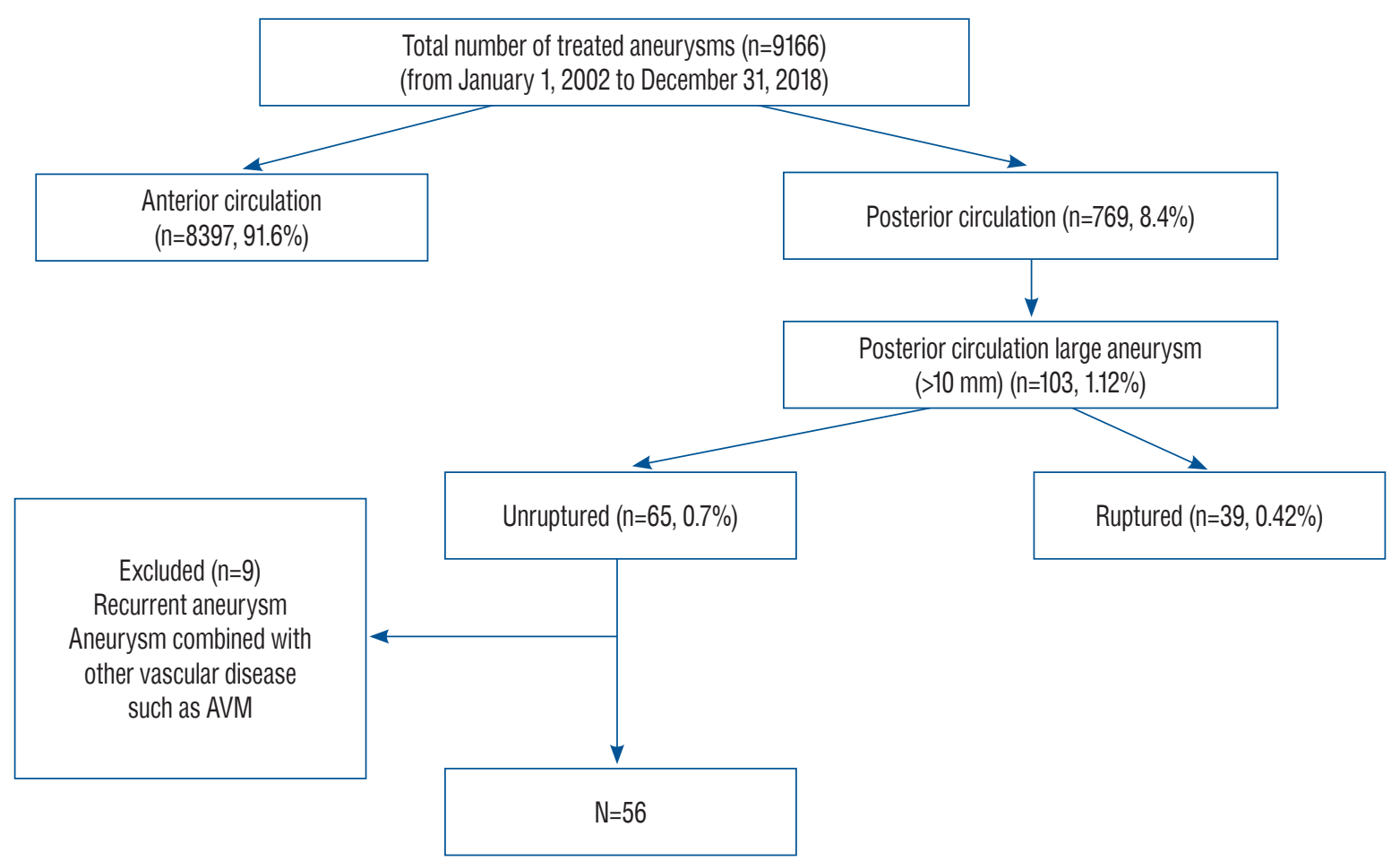

Fig. 1. Patient enrollment. A total of 56 patients who presented with a large unruptured posterior circulation aneurysm between January 2002 and December 2018 were enrolled. AVM : arteriovenous malformation. 
years for transcranial surgery. Magnetic resonance imaging were obtained at 1 or 3 months, 1 year after treatment, and then every 1 or 2 years for transcranial surgery for EVT.

Aneurysm size was defined as the maximal aneurysmal dome size for saccular aneurysms and as the maximal length of a fusiform aneurysm on two-dimensional imaging of catheter angiography, if measurement in catheter angiography was not feasible, computed tomography angiography was used for measurement. To minimize measurement error, the size of each aneurysm was measured three times by three different board-certified neurosurgeons at diagnosis, and the mean value was recorded.

Pre- and post-treatment functional status were assessed using the Glasgow outcome scale (GOS).

\section{Statistical analysis}

The follow-up period was defined as the interval between the dates of initial treatment and the last outpatient clinic visit or brain imaging. Subgroup comparisons were performed using Student's t-test and the chi-square test. Potential predictors of post-treatment complications and functional outcome, including age, sex, size of aneurysm, dome-neck ratio, thrombosed aneurysm, treatment modality, brainstem compression, and hypertension, were analyzed using binary logistic regression analysis.

All statistical analyses were conducted using SPSS ver. 21.0 (IBM Corp., Armonk, NY, USA). A $p$-value $<0.05$ was considered statistically significant.
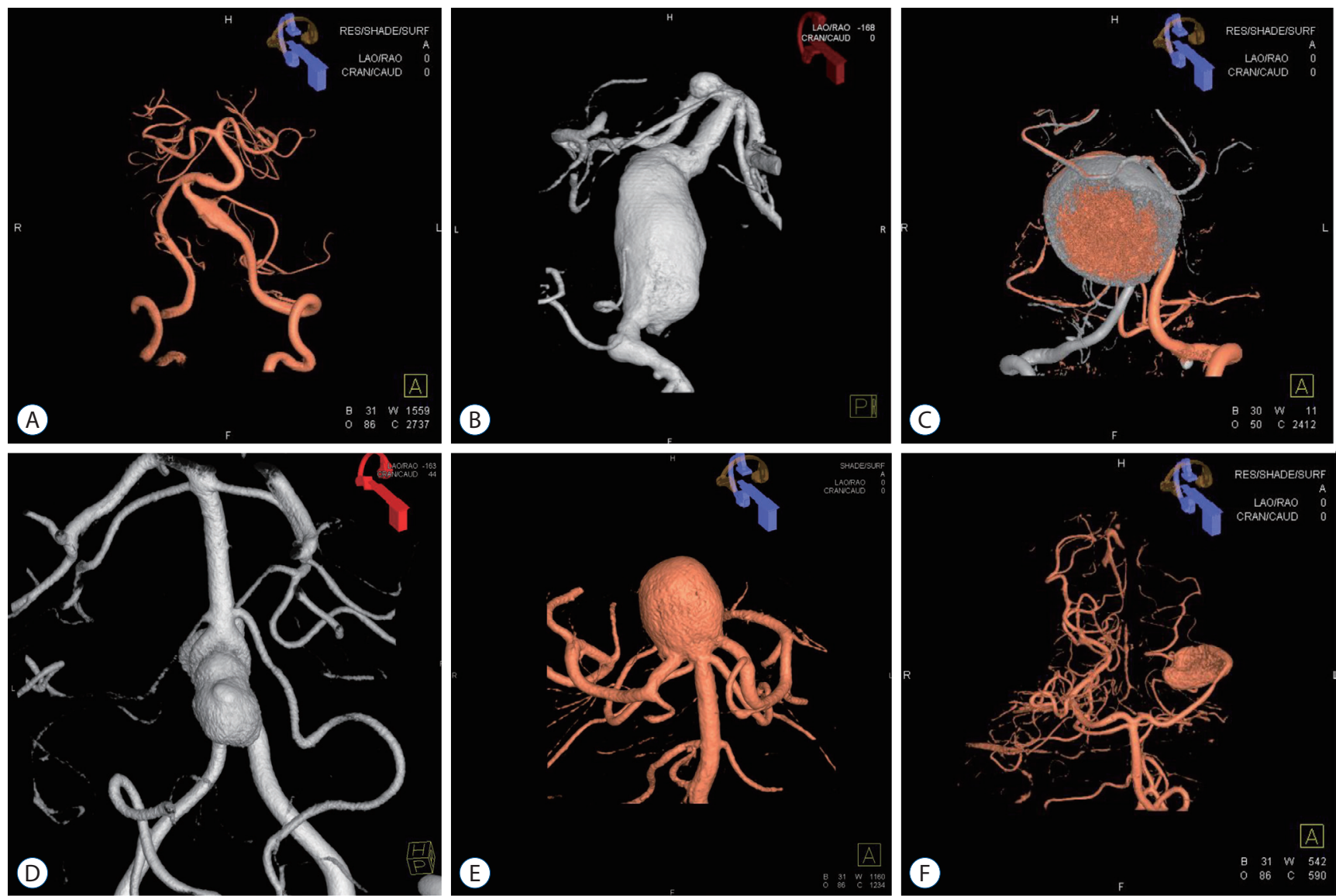

Fig. 2. Representative cases of large unruptured posterior circulation aneurysms. A : Left vertebral artery aneurysm incorporating the posterior inferior cerebellar artery. This aneurysm was partially thrombosed and compressed the brainstem. B : Large vertebrobasilar junction aneurysm incorporating multiple perforators and the posterior inferior cerebellar artery. C : Large basilar trunk aneurysm that severely compressed the brainstem. D : Large bilobed vertebral artery aneurysm. E : Basilar tip aneurysm incorporating both posterior cerebral arteries and superior cerebellar arteries. $\mathrm{F}$ : Large posterior cerebral artery P3 segment aneurysm. 


\section{RESULTS}

\section{Baseline characteristics of the enrolled patients}

There were 18 (32.1\%) male and 38 (67.9\%) female patients. The mean patient age was 53.4 years. The most common location was the vertebral artery, followed by the basilar tip and the posterior cerebral artery (PCA; Fig. 2). The most common presenting symptom was headache (46.4\%). The mean size of the 56 aneurysms was $15.6 \mathrm{~mm}$, and $36(64.3 \%)$ of them were of saccular type. Eleven of 56 (19.6\%) aneurysms were partially thrombosed, and 35 (62.5\%) of them showed brainstem compression. Twenty-six patients (48.4\%) had hypertension. The median follow-up duration was 29 months. Detailed characteristics of including patients demonstrated in Table 1.

\section{Treatment modality and outcome}

The detailed of treatment modalities and outcomes demonstrated in Table 2. Eighteen patients (32.1\%) were treated by transcranial surgery and 38 (67.9\%) were treated by EVT. Among the patients treated by transcranial surgery, two underwent extracranial-intracranial (EC-IC) arterial bypass surgery (one patient : occipital artery-posterior inferior cerebellar artery; the other patient : superficial temporal artery-PCA) and additional intraoperative endovascular trapping of the aneurysm. In the 38 patients (67.9\%) treated by EVT, stent-assisted coil embolization was the most commonly used method. Representative cases are presented in Fig. 3. Post-treatment complication occurred in 16 patients (28.6\%). Common complications of transcranial surgery were perforators occlusion, intracerebral hemorrhage, and common complication of EVT were embolic infarction parent artery occlusion. The posttreatment complication rate was higher in transcranial surgery group than EVT group, however, there was no statistically significant difference in the post-treatment complication rate between the transcranial surgery and EVT groups (38.9\% vs. $23.7 \%$, respectively, $p=0.22$ ). Posttreatment complication cases demonstrated on Table 3 and representative cases image findings presented on Fig. 4. Complete obliteration at immediate posttreatment period was achieved in 30 patients (53.6\%), with there again being no statistically significant difference between the transcranial and EVT groups (55.6\% vs. $52.6 \%, p=0.92)$. Recurrence occurred in 17 patients (30.4\%), with the rate of recurrence being significantly higher in the EVT group than in the transcranial surgery group $(39.5 \%$ vs.
$11.1 \%$, respectively, $p=0.03$ ).

There was one mortality case in EVT group. This patient underwent endovascular trapping of vertebral artery for vertebral artery aneurysm, after 22 days after treatment, unknown cause sudden cardiac arrest was occurred. Forty-four (84\%) of

Table 1. Basal characteristics of the enrolled patients

\begin{tabular}{|c|c|}
\hline Variable & Value $(n=56)$ \\
\hline \multicolumn{2}{|l|}{ Sex } \\
\hline Male & $18(32.1)$ \\
\hline Female & $38(67.9)$ \\
\hline \multicolumn{2}{|l|}{ Age (years) } \\
\hline Mean & $53.4(23-79)$ \\
\hline \multicolumn{2}{|l|}{ Location of aneurysm } \\
\hline Basilar tip & 17 (30.4) \\
\hline Basilar trunk & $1(1.8)$ \\
\hline Vertebral artery & $20(35.7)$ \\
\hline PCA & $9(16.1)$ \\
\hline SCA & $5(8.9)$ \\
\hline PICA & $3(5.4)$ \\
\hline Vertebrobasilar junction & $1(1.8)$ \\
\hline \multicolumn{2}{|l|}{ Presenting symptoms } \\
\hline Headache & $26(46.4)$ \\
\hline Motor weakness & $1(1.8)$ \\
\hline Cranial nerve symptom & $1(1.8)$ \\
\hline Dizziness & $2(3.6)$ \\
\hline Loss of consciousness & $1(1.8)$ \\
\hline Dysarthria & $1(1.8)$ \\
\hline Sensory disturbance & $1(1.8)$ \\
\hline Unrelated ICH & $5(8.9)$ \\
\hline Incidental findings & $18(32.1)$ \\
\hline \multicolumn{2}{|l|}{ Type of aneurysm } \\
\hline Saccular aneurysm & $36(64.3)$ \\
\hline Fusiform aneurysm & $20(35.7)$ \\
\hline \multicolumn{2}{|l|}{ Size of aneurysm (mm) } \\
\hline Mean & $15.6(10-37)$ \\
\hline Thrombosed aneurysm & 11 (19.6) \\
\hline Hypertension & $26(48.4)$ \\
\hline Brainstem compression & $35(62.5)$ \\
\hline \multicolumn{2}{|l|}{ Follow-up period (months) } \\
\hline Median & $29(1-122)$ \\
\hline
\end{tabular}

Values are presented as number (\%), mean (range), or median (range). PCA : posterior cerebral artery, SCA : superior cerebellar artery, PICA : posterior inferior cerebellar artery, ICH : intracerebral hemorrhage 
56 patients showed a favorable functional outcome (GOS 4 and 5 ), while $16 \%$ showed an unfavorable outcome (GOS $\leq 3$;

Table 2. Treatment modality and outcomes of large unruptured posterior circulation aneurysms

\begin{tabular}{|c|c|c|}
\hline Variable & Value $(n=56)$ & $p$-value \\
\hline \multicolumn{3}{|l|}{ Treatment } \\
\hline Transcranial & $18(32.1)$ & \\
\hline Clipping & $8(44.4)$ & \\
\hline $\begin{array}{l}\text { Surgical trapping without } \\
\text { revascularization }\end{array}$ & $2(11.1)$ & \\
\hline $\begin{array}{l}\text { Clipping/trapping with } \\
\text { revascularization }\end{array}$ & $4(22.2)$ & \\
\hline Wrapping & $1(5.6)$ & \\
\hline $\begin{array}{l}\text { EC-IC bypass for aneurysm flow } \\
\text { diversion }\end{array}$ & $1(5.6)$ & \\
\hline $\begin{array}{l}\text { EC-IC bypass with additional } \\
\text { endovascular trapping }\end{array}$ & $2(11.1)$ & \\
\hline Endovascular & $38(67.9)$ & \\
\hline Coil embolization & $7(18.4)$ & \\
\hline Stent-assisted coil embolization & $18(47.4)$ & \\
\hline Endovascular trapping & $8(21.1)$ & \\
\hline Pipeline flow diverter & $1(2.6)$ & \\
\hline Stenting & $4(10.5)$ & \\
\hline \multicolumn{3}{|l|}{ Location of aneurysm } \\
\hline Transcranial & 18 & \\
\hline Basilar tip & $6(33.3)$ & \\
\hline Basilar trunk & $1(5.6)$ & \\
\hline Vertebral artery & $3(16.7)$ & \\
\hline PCA & $3(16.7)$ & \\
\hline SCA & $3(16.7)$ & \\
\hline PICA & $2(11.1)$ & \\
\hline Endovascular & 38 & \\
\hline Basilar tip & $11(28.9)$ & \\
\hline Vertebral artery & $17(44.7)$ & \\
\hline PCA & $6(15.8)$ & \\
\hline SCA & $2(5.3)$ & \\
\hline PICA & $1(2.6)$ & \\
\hline VB junction & $1(2.6)$ & \\
\hline Post-treatment complication & $16(28.6)$ & \\
\hline Transcranial surgery & $7 / 18(38.9)$ & \\
\hline Perforators occlusion & 3 & \\
\hline Embolic infarction & 1 & \\
\hline Venous infarction & 1 & \\
\hline
\end{tabular}

Table 4).

Table 2. Continued

\begin{tabular}{|c|c|c|}
\hline Variable & Value $(n=56)$ & $p$-value \\
\hline Intracerebral hemorrhage & 2 & \\
\hline Intra-aneurysmal hemorrhage & 1 & \\
\hline Endovascular surgery & 9/38 (23.7) & \\
\hline Parent artery occlusion & 2 & \\
\hline Perforators occlusion & 2 & \\
\hline Embolic infarction & 4 & \\
\hline Hydrocephalus & 1 & \\
\hline $\begin{array}{l}\text { Transcranial surgery vs. endovascular } \\
\text { surgery }\end{array}$ & & 0.22 \\
\hline \multicolumn{3}{|l|}{$\begin{array}{l}\text { Obliteration of aneurysm (at immediate } \\
\text { posttreatment period) }\end{array}$} \\
\hline \multicolumn{3}{|l|}{ Total } \\
\hline Complete obliteration & $30(53.6)$ & \\
\hline Incomplete obliteration & $26(46.4)$ & \\
\hline Transcranial surgery & 18 & \\
\hline Complete obliteration & $10(55.6)$ & \\
\hline Incomplete obliteration & $8(44.4)$ & \\
\hline Endovascular surgery & 38 & \\
\hline Complete obliteration & $20(52.6)$ & \\
\hline Incomplete obliteration & $18(47.4)$ & \\
\hline $\begin{array}{l}\text { Transcranial surgery vs. endovascular } \\
\text { surgery }\end{array}$ & & 0.92 \\
\hline Recurrence of aneurysm & $17(30.4)$ & \\
\hline Transcranial surgery & 2/18 (11.1) & \\
\hline Endovascular surgery & 15/38 (39.5) & \\
\hline $\begin{array}{l}\text { Transcranial surgery vs. endovascular } \\
\text { surgery }\end{array}$ & & 0.03 \\
\hline
\end{tabular}

Treatment of recurrence

Coil embolization

$6(35.3)$

Stent-assisted coil embolization

Clipping with EC-IC bypass

$1(5.9)$

Transcranial trapping

$1(5.9)$

Observation

$7(41.2)$

Mortality

$1(1.8)$

Values are presented as number (\%). EC-IC : extracranial-intracranial, PCA : posterior cerebral artery, SCA : superior cerebellar artery, PICA : posterior inferior cerebellar artery 

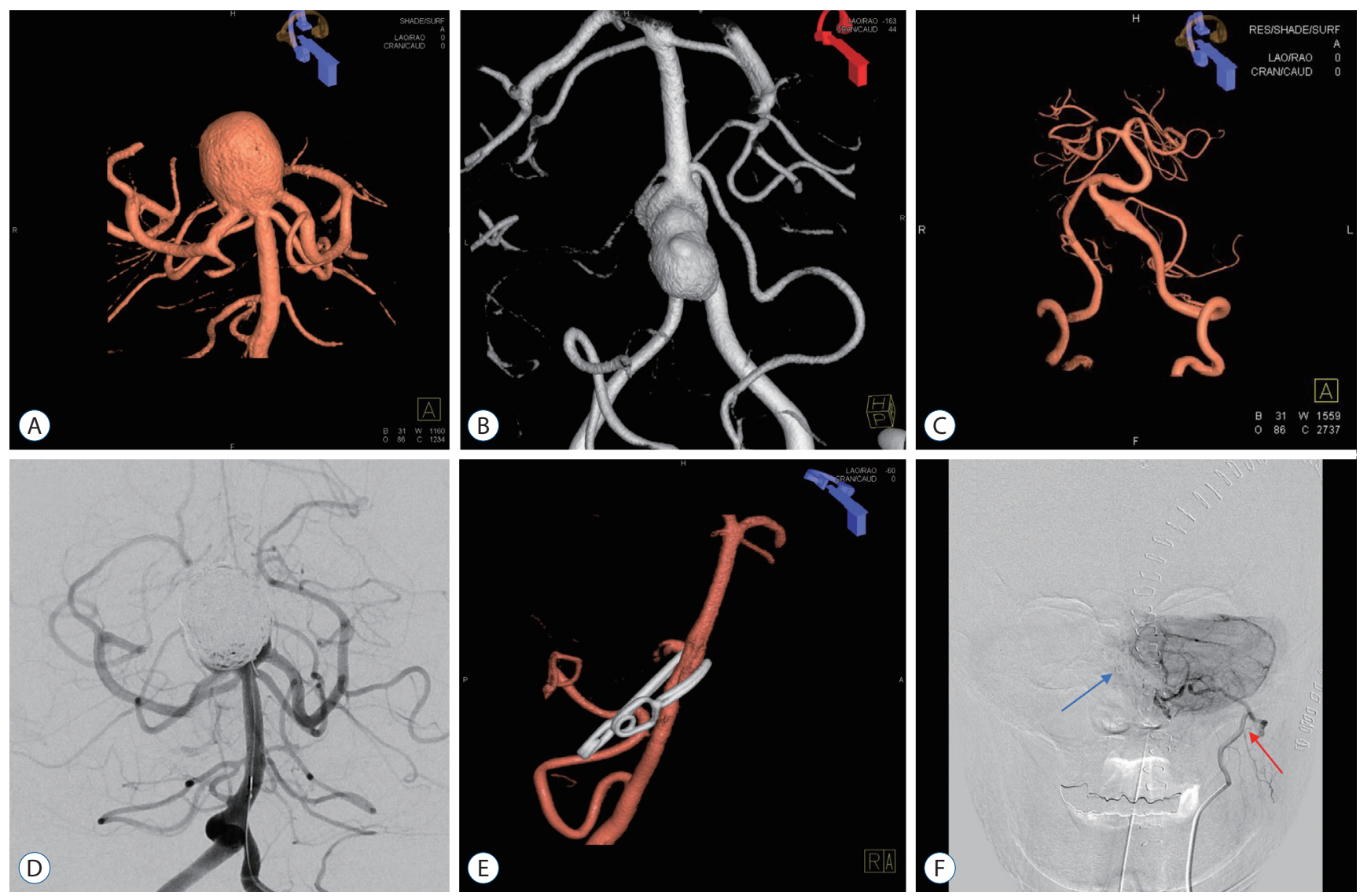

Fig. 3. Treatment of large unruptured posterior circulation aneurysms. Various treatment strategies were used for large unruptured posterior circulation aneurysms. A and D : Large basilar tip aneurysm treated by coil embolization. A large coil mass can be seen in the aneurysm. B and E : Lage bilobed vertebral artery aneurysm treated by direct clipping through the far-lateral transcondylar approach. $\mathrm{C}$ and $\mathrm{F}$ : Large partially thrombosed aneurysm that incorporated the posterior inferior cerebellar artery (PICA). An occipital artery-PICA end-to-side anastomosis (red arrow) was performed, and additional coil trapping of the left vertebral artery (blue arrow) was undertaken.

\section{Predictors of post-treatment complication and worsening of functional status}

We analyzed possible predictors of post-treatment complication and worsening of functional status, analysis of was performed in separated subgroup which divided according to type of aneurysm (saccular vs. fusiform aneurysm). Sex, age, dome-neck ratio, size of aneurysm, thrombosed aneurysm, brainstem compression, and hypertension were not statistically significant predictors of post-treatment complication and worsening of functional status in both subgroups. EVT was only significant negative predictor for worsening of functional status in saccular aneurysm group (odds ratio $=0.15 ; p=0.05$ ). The results of predictor analysis demonstrated in Table 5.

\section{DISCUSSION}

Posterior circulation aneurysms are relatively rare, accounting for $3.8-15 \%$ of all intracranial aneruysms ${ }^{13)}$, and the incidence of large $(>10 \mathrm{~mm})$ posterior circulation aneurysms is not well known. In our series, the incidence of a posterior circulation aneurysm was $8.4 \%$, and the incidence of a large posterior circulation aneurysm was $1.12 \%$.

The rupture risks for posterior circulation aneurysms and large aneurysms are higher than those for small and anterior circulation aneurysms ${ }^{7}$. In the case of a large ruptured posterior circulation aneurysm, there is no doubt about the requirement for obliteration of the aneurysm to prevent rebleeding. However, there has been some debate over the appropriate treatment for large unruptured posterior circulation aneurysms. Until now, a clinical report on the outcomes of large 


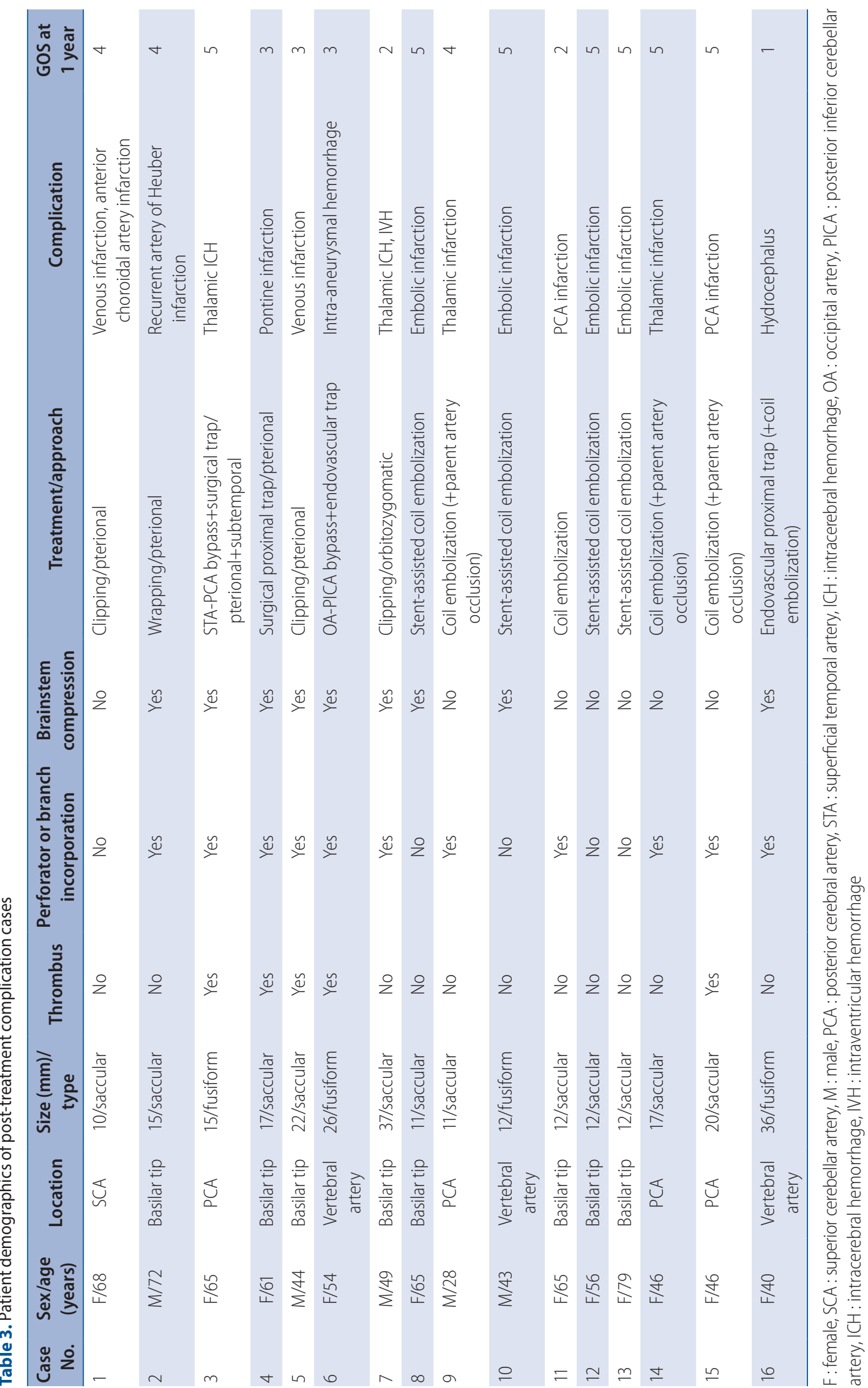



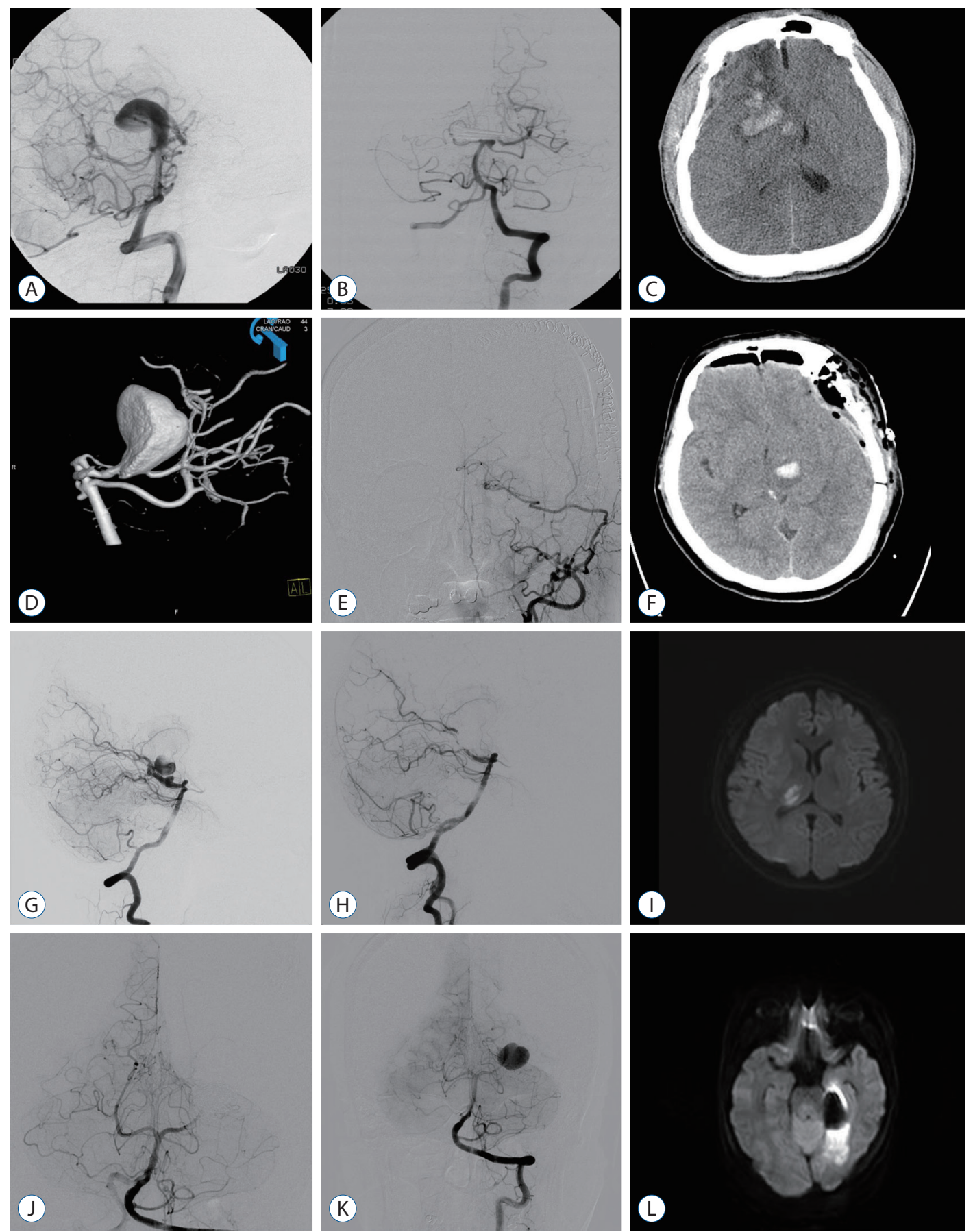

Fig. 4. Image findings of posttreatment complication cases. A-C : Case \#5 of Table 3. A and B : Patient underwent direct clipping of large thrombosed basilar tip aneurysm. C : In postoperative CT scan, postoperative venous infarction was occurred, low density of right frontal lesion with scattered hematoma were seen. Decreased consciousness and left side motor weakness were noted, patient treated conservatively. D-F : Case \#3 of Table 3. D and $\mathrm{E}$ : Patient underwent superficial temporal artery-superior cerebellar artery bypass with microsurgical trap of posterior cerebral artery. $\mathrm{F}$ : Intracerebral hemorrhage of left thalamus was seen in postoperative computed tomography scan. Right side motor weakness (grade IV) was seen, however patient recovered very well. G-I: Case \#14 of Table 3. G and H : Patient underwent coil embolization with parent artery occlusion for right PCA aneurysm, patient was neurologically stable during preoperative balloon test occlusion of PCA. I : Right thalamic infarction was noted in diffusion MRI. Left side motor weakness (grade IV) was seen, however, patient recovered very well. J-L : Case \#15 of Table 3. J and K : Patient underwent coil embolization and parent artery occlusion for left PCA aneurysm. L : Postoperative left PCA territory infarction was noted in diffusion MRI. Patient was neurologically stable during preoperative balloon test occlusion of PCA. Patient recovered well except visual field defect. PCA : posterior cerebral artery, MRI : magnetic resonance imaging. 
unruptured posterior circulation aneurysms has been lacking. Moreover, there has been little reporting of the known predictors of post-treatment outcomes for large unruptured posterior circulation aneurysms.

Although the treatment-related morbidity rate of posterior circulation aneurysms has progressively decreased, the posttreatment complication rate of large and giant intracranial aneurysms remains high. Cagnazzo et al. ${ }^{4)}$ reported a 16-30\% post-treatment complication rate for very large and giant in-

Table 4. Pretreatment and posttreatment functional status of the enrolled patients

\begin{tabular}{lcc}
$\begin{array}{c}\text { Glasgow outcome } \\
\text { scale }\end{array}$ & At admission & $\begin{array}{c}\text { At posttreatment } \\
\text { 3-month }\end{array}$ \\
\hline 1 & $0(0.0)$ & $1(1.8)$ \\
2 & $0(0.0)$ & $2(3.6)$ \\
3 & $4(7.1)$ & $6(10.7)$ \\
4 & $9(16.1)$ & $3(5.4)$ \\
5 & $43(76.8)$ & $44(78.6)$ \\
\hline
\end{tabular}

Values are presented as number (\%) tracranial aneurysm. Furthermore, the treatment-related morbidity and mortality rates of posterior circulation aneurysms are higher than those for anterior circulation aneurysms ${ }^{10)}$. With the need to consider the high post-treatment complication rate of large posterior circulation aneurysms, the decision on treatment approach for such large aneurysms is very complicated, especially in unruptured cases. In our study, the overall post-treatment complication rate was $28.6 \%$, with the rate being higher for transcranial surgery than for EVT, although the difference was not statistically significant. Seventeen patients underwent EVT before 2010 and 21 patients underwent EVT from 2010 to 2018. Before 2010, five of 17 patients (29.4\%) showed post-procedural complications after EVT and four of 21 (19\%) showed post-procedural complication from 2010 to 2018. The technique and device of EVT has been developed considerably after 2010. However, this result did not show statistical significance $(p=0.7)$. Although not all post-treatment complications lead to worsening of functional outcomes, the high complication rate may be the most important consideration in the treatment of large unruptured poste-

Table 5. Predictors of deterioration in functional status and post-treatment complications (univariate analysis)

\begin{tabular}{|c|c|c|c|c|c|c|c|c|c|c|c|c|}
\hline \multirow{3}{*}{ Variable } & \multicolumn{6}{|c|}{ Saccular aneurysm } & \multicolumn{6}{|c|}{ Fusiform aneurysm } \\
\hline & \multicolumn{3}{|c|}{$\begin{array}{l}\text { Post-treatment } \\
\text { complications }\end{array}$} & \multicolumn{3}{|c|}{$\begin{array}{c}\text { Worsening of } \\
\text { functional status }\end{array}$} & \multicolumn{3}{|c|}{$\begin{array}{l}\text { Post-treatment } \\
\text { complications }\end{array}$} & \multicolumn{3}{|c|}{$\begin{array}{c}\text { Worsening of } \\
\text { functional status }\end{array}$} \\
\hline & $\begin{array}{c}\text { OR } \\
{[\operatorname{Exp}(ß)]}\end{array}$ & $95 \% \mathrm{Cl}$ & $p$-value & $\begin{array}{c}\text { OR } \\
{[\operatorname{Exp}(ß)]}\end{array}$ & $95 \% \mathrm{Cl}$ & $p$-value & $\begin{array}{c}\text { OR } \\
{[\operatorname{Exp}(ß)]}\end{array}$ & $95 \% \mathrm{Cl}$ & $p$-value & $\begin{array}{c}\text { OR } \\
{[\operatorname{Exp}(ß)]}\end{array}$ & $95 \% \mathrm{Cl}$ & $p$-value \\
\hline \multicolumn{13}{|l|}{ Sex } \\
\hline Female & 0.9 & $0.2-4.3$ & 0.98 & 0.8 & $0.1-5.5$ & 0.87 & 1.8 & $0.1-21.4$ & 0.64 & $2.90 E+08$ & NA & 0.99 \\
\hline \multicolumn{13}{|l|}{ Age (years) } \\
\hline$\geq 65$ & 2 & $0.3-11.7$ & 0.44 & 1 & $0.0-10.5$ & 1 & NA & & & NA & & \\
\hline \multicolumn{13}{|l|}{ Size (mm) } \\
\hline $15-20$ & 1.6 & $0.2-9.2$ & 0.59 & 1 & $0.0-12.1$ & 0.96 & $4.00 \mathrm{E}+08$ & NA & 0.99 & 1 & NA & 1 \\
\hline$>20$ & 1.6 & $0.2-9.2$ & 0.59 & 2.5 & $0.3-19.5$ & 0.37 & $4.80 \mathrm{E}+08$ & NA & 0.99 & $1.60 \mathrm{E}+08$ & NA & 1 \\
\hline \multicolumn{13}{|l|}{ Dome-neck ratio } \\
\hline$>1$ & $8.50 E+08$ & NA & 0.99 & $3.00 \mathrm{E}+07$ & NA & 0.99 & NA & NA & NA & NA & NA & NA \\
\hline $\begin{array}{l}\text { Thrombosed } \\
\text { aneurysm }\end{array}$ & 2 & $0.3-11.7$ & 0.44 & 3.2 & $0.4-23.9$ & 0.24 & 4.3 & $0.4-44.4$ & 0.2 & 3.5 & $0.1-69.3$ & 0.41 \\
\hline \multicolumn{13}{|c|}{ Treatment modality } \\
\hline Endovascular & 0.5 & $0.1-2.4$ & 0.44 & 0.15 & $0.0-1.0$ & 0.05 & 0.1 & $0-1.3$ & 0.08 & 0.5 & $0.0-9.4$ & 0.64 \\
\hline $\begin{array}{l}\text { Brainstem } \\
\text { compression }\end{array}$ & 1.4 & $0.3-5.8$ & 0.58 & 1.7 & $0.2-11.0$ & 0.55 & $5.80 E+08$ & NA & 0.99 & $2.40 \mathrm{E}+08$ & NA & 0.99 \\
\hline Hypertension & 2 & $0.5-8.3$ & 0.3 & 1 & $0.1-5.7$ & 1 & 1.6 & $0.1-16.1$ & 0.65 & 1.5 & $0.1-29.4$ & 0.76 \\
\hline
\end{tabular}

OR : odds ratio, $\mathrm{Cl}$ : confidence interval, $\mathrm{NA}$ : not applicable 
rior circulation aneurysm. For this reason, some clinicians advocate conservative management including aggressive control of hypertension or antiplatelet medication for thrombosed aneurysm in unruptured large posterior circulation aneurysm.

There has been relentless debate over the superiority of transcranial surgery or EVT for intracranial aneurysm. In a recent meta-analysis, Tsianaka et al. ${ }^{12)}$ reported no superiority between transcranial surgery and EVT in the treatment of posterior circulation aneurysm. However, their report lacked a subgroup analysis for large posterior circulation aneurysms ${ }^{12)}$.

Direct surgical clipping of large posterior circulation aneurysms is not always feasible. Large aneurysms frequently harbor crucial perforators and an unidentifiable neck. Surgical trapping of the aneurysm may also be a possible treatment option, but this requires surgical revascularization and a skull base approach for large posterior circulation aneurysms. In the case of large posterior circulation aneurysms that are unclippable and untrappable, a surgical flow alteration such as distal or proximal trapping of parent artery after EC-IC bypass surgery could be a feasible treatment option. Lee et al. ${ }^{8)}$ reported favorable treatment outcomes for surgical flow diversion for intracranial aneurysms that were unclippable, untrappable, and uncoilable. They reported a 75\% rate of complete obliteration after surgical flow diversion, although the complication rate of surgical flow diversion was $18 \%{ }^{8)}$. The high morbidity of transcranial surgery remains a great challenge.

In the endovascular era, many clinicians have advocated the use of EVT to treat posterior circulation aneurysm ${ }^{6,9,12)}$. In our series, more than $60 \%$ of patients were treated by EVT, and the complete obliteration and post-treatment complication rates of EVT were comparable to those of transcranial surgery. A flow diverter stents may be a novel endovascular option for large posterior circulation aneurysm. Bhogal et al. ${ }^{3)}$ reported a $75 \%$ complete obliteration rate for flow diverter treatment for unruptured posterior circulation fusiform aneurysms. In Korea, flow diverter stent has been covered by the National Health Insurance Service since from 2014 for unruptured aneurysm $15 \mathrm{~mm}$ or larger, or dissecting vertebral artery aneurysm in posterior circulation aneurysm. For the reason, just one flow diverter stent case was included in this study. Flow diverter stent showed clear beneficial effect in complex unruptured aneurysm treatment. Further study of flow diverter stent for large or giant posterior circulation aneurysm should be needed.

In our series, various transcranial surgical methods were used. Direct clipping was performed in eight of 18 cases (44.4\%), with the others being treated by surgical trapping with revascularization, surgical flow alteration, or wrapping. In two cases, combined transcranial-EVTs were performed to treat the aneurysm (surgical revascularization and additional intraoperative endovascular trapping, Fig. 3C).

Various endovascular methods have been used recently, and only seven of 38 patients (18.4\%) were treated with coil embolization alone. The most commonly used endovascular method was stent-assisted coil embolization, and only one patient was treated by flow diverter stents (Pipeline embolization device; ev3, Irvine, CA, USA). The complete obliteration and post-treatment complication rates of transcranial surgery and EVT did not show statistically significant differences (complete obliteration : $53.6 \%$ vs. $55.6 \%$, respectively, $p=0.92$; posttreatment complications : $38.9 \%$ vs $23.7 \%, p=0.22$ ). The posttreatment complication rate was higher in transcranial surgery group than in EVT group in our series. We should cautiously interpret our result because there was limitation of small case number. Also, in our institute, we have not had adequate experience of flow diverter stents which is novel treatment option for large posterior circulation aneurysm due to limited number of patients and national health care-insurance conflicts of our country.

When it comes to the recurrence rate of aneurysms, there was a difference between transcranial surgery and EVT in our series, with the recurrence rate of EVT being higher than that of transcranial surgery (39.5\% vs $11.1 \%, p=0.03)$. Tsianaka et al. ${ }^{12)}$ also reported a high recurrence rate for EVT in posterior circulation aneurysms. In our experience, when it comes to the durability of treatment, transcranial surgery is better than EVT in large unruptured posterior circulation aneurysms. Although EVT harbors the inherent advantage of minimal invasiveness and high accessibility, when its high recurrence rate is considered, EVT may not always be the ideal treatment. Moreover, in some cases (Fig. 2), revascularization may be needed to obliterate the aneurysm. In our institute, the treatment decision for large unruptured posterior circulation aneurysms is made by discussion between the neurosurgeon (transcranial and endovascular) and neuroradiologist to yield the best treatment outcome.

The post-treatment functional outcome is the most impor- 
tant clinical outcome in the treatment of unruptured aneurysm. In our series, $84 \%$ of enrolled patients showed a favorable functional outcome (GOS 4 and 5), while 16\% showed an unfavorable outcome. Recently, Chua et al. ${ }^{5)}$ reported a favorable overall treatment outcome rate of $97.8 \%$ for unruptured aneurysms treated between 2007 and 2013. Although our study evaluated large posterior circulation aneurysms, an unfavorable functional outcome rate over $15 \%$ is an important consideration in treatment decision making.

The predictors of treatment outcome for large unruptured posterior circulation aneurysms are not well known. In an early report, age was the only independent predictor of the surgical outcomes of intracranial aneurysm ${ }^{2)}$. Park et al. ${ }^{11)}$ reported high Hunt-Hess grade, advanced age, and intraventricular hemorrhage to be significant predictors of treatment outcomes for intracranial aneurysms; however, they included both ruptured and unruptured aneurysms in patients aged 65 years and older. In the recent report of Ban et al. ${ }^{1)}$, it was reported that intracerebral hemorrhage, aneurysmal size $\geq 20 \mathrm{~mm}$, intraventricular hemorrhage, age $>64$ years, hydrocephalus, and a posterior circulation location were significant predictors for a ruptured aneurysm. In our study, EVT was only significant negative predictor for worsening of functional status in saccular aneurysm group. Although, this result should be cautiously interpreted, it might imply the posttreatment complications of EVT were less severe than transcranial surgery.

We could not draw meaningful conclusion due to small number of enrolled patients. The rate of posttreatment complication was high in treatment of large posterior circulation aneurysm. Clinician should inform "risks and benefits" of treatment to patients and their caretakers. To our experiences, in case of thrombosed aneurysm, aneurysm showed mass effect, aneurysm incorporated critical branches and perforators, microsurgical treatment including revascularization or combined microsurgical/EVT may be better treatment choice than EVT. Also, parent arterial occlusion via EVT should be cautiously considered even patient showed stable neurological status during balloon test occlusion. However, we have not had adequate experience of flow diverter stents for large posterior circulation aneurysm, careful observation for outcomes of flow diverter stents will be needed.

\section{Limitations and strengths}

Our current study has some limitations of note. In the first instance, it was a retrospective study that included only 56 patients with large unruptured posterior circulation aneurysms, and it is subject to the limitations inherent to any retrospective design, which preclude any meaningful multivariate analysis of outcomes or predictors. The study series also spanned 16 years, during which there have been refinements in the transcranial surgical technique and new developments in endovascular instruments. Also, we included both saccular and fusiform large aneurysm of posterior circulation, the type of aneurysm plays role as confounding factor. There was also a difference in the aneurysm locations between the transcranial surgery and EVT groups, which could also have affected posttreatment morbidity and outcomes. For this reason, caution should be taken in interpretation of our result of study.

Our study also had some notable strengths, including our finding that the treatment of large unruptured posterior circulation aneurysms has a relatively high morbidity rate and a high rate of unfavorable post-treatment functional outcomes. Although we did not show any superiority between transcranial surgery and EVT in terms of the complication rate or complete obliteration, transcranial surgery showed higher treatment durability. Although we have been unable to draw any meaningful conclusions to assist with future treatment guidelines, our analysis indicates that EVT is the only negative prognostic indicator in terms of worsening of functional status.

In the case of large unruptured posterior circulation aneurysms, the treatment strategy should be chosen on a case-bycase basis, and the cooperative endeavor of both transcranial and endovascular teams may be needed. We therefore believe that the data from our current single-center series make a valuable contribution to the available literature on these extremely rare aneurysms.

\section{CONCLUSION}

Unruptured large posterior circulation aneurysms are very rare. Treatment of these aneurysms harbors an inherent risk of high morbidity. We found no superiority between transcranial surgery and EVT in terms of complication and obliteration rates, although transcranial surgery showed higher treatment durability than EVT. Future refinement of both transcranial surgery and EVT will be needed to achieve better post-treatment outcomes. 


\section{CONFLICTS OF INTEREST}

No potential conflict of interest relevant to this article was reported.

\section{INFORMED CONSENT}

This type of study does not require informed consent.

\section{AUTHOR CONTRIBUTIONS}

\author{
Conceptualization : JB, WP \\ Data curation : JB \\ Formal analysis : JB \\ Methodology : JB, WP, JCP, JSA \\ Project administration : JB \\ Visualization : JB, WP \\ Writing - original draft : JB \\ Writing - review \& editing : JB, WP, JCP, JSA
}

\section{ORCID}

Joonho Byun https://orcid.org/0000-0003-0687-3286

Wonhyoung Park https://orcid.org/0000-0002-9977-0595

Jung Cheol Park https://orcid.org/0000-0001-6677-455X

Jae Sung Ahn https://orcid.org/0000-0001-6134-6214

\section{- Acknowledgements}

We appreciate to Prof. Byung Duk Kwun who is our eternal teacher, founder of cerebrovascular surgery section of AMC Neurosurgery and great neurosurgeon. We always remember his teaching, attitude of neurosurgeon, and life philosophy. We were his students, now we are great honored to be able to work as his colleagues. We also thank Jeong Hyun Oh, a rhinologist in Daejeon (Coen Clinic), who gave us valuable advice and help.

\section{References}

1. Ban VS, El Ahmadieh TY, Aoun SG, Plitt AR, Lyon KA, Eddleman C, et al. : Prediction of outcomes for ruptured aneurysm surgery: the Southwestern aneurysm severity index. Stroke 50 : 595-601, 2019

2. Besser $M$, Khurana VG : Management of giant intracranial aneurysms of the posterior circulation. J Clin Neurosci 5 : 161-168, 1998

3. Bhogal P, Pérez MA, Ganslandt O, Bäzner $H$, Henkes $H$, Fischer $S$ : Treatment of posterior circulation non-saccular aneurysms with flow diverters: a single-center experience and review of 56 patients. J Neurointerv Surg 9 : 471-481, 2017

4. Cagnazzo F, Mantilla D, Rouchaud A, Brinjikji W, Lefevre PH, Dargazanli $C$, et al. : Endovascular treatment of very large and giant intracranial aneurysms: comparison between reconstructive and deconstructive techniques-a meta-analysis. AJNR Am J Neuroradiol 39 : 852-858, 2018

5. Chua MH, Griessenauer CJ, Stapleton CJ, He L, Thomas AJ, Ogilvy CS : Documentation of improved outcomes for intracranial aneurysm management over a 15-year interval. Stroke 47 : 708-712, 2016

6. Eller JL, Dumont TM, Mokin M, Sorkin GC, Levy El, Snyder KV, et al. : Endovascular treatment of posterior circulation aneurysms. Neurol Res $36: 339-343,2014$

7. International Study of Unruptured Intracranial Aneurysms Investigators : Unruptured intracranial aneurysms--risk of rupture and risks of surgical intervention. N Engl J Med 339 : 1725-1733, 1998

8. Lee SH, Ahn JS, Kwun BD, Park W, Park JC, Roh SW : Surgical flow alteration for the treatment of intracranial aneurysms that are unclippable, untrappable, and uncoilable. J Korean Neurosurg Soc 58 : 518-527, 2015

9. Lempert TE, Malek AM, Halbach VV, Phatouros CC, Meyers PM, Dowd $\mathrm{CF}$, et al. : Endovascular treatment of ruptured posterior circulation cerebral aneurysms. Clinical and angiographic outcomes. Stroke 31 : 100110,2000

10. Ng P, Khangure MS, Phatouros CC, Bynevelt M, ApSimon H, McAuliffe $W$ : Endovascular treatment of intracranial aneurysms with guglielmi detachable coils: analysis of midterm angiographic and clinical outcomes. Stroke $33:$ :210-217, 2002

11. Park JH, Kim YI, Lim YC : Clinical outcomes of treatment for intracranial aneurysm in elderly patients. J Cerebrovasc Endovasc Neurosurg 16 : 193-199, 2014

12. Tsianaka E, Al-Shawish A, Potapov A, Fountas K, Spyrou M, Konovalov $\mathrm{N}$ : Clipping versus coiling in posterior circulation intracranial aneurysms: a meta-analysis. Chin Neurosurg J 5 : 1, 2019

13. Zhao J, Wang S, Yang L, Zhao Y : Clinical experience of 153 patients with posterior circulation aneurysms. J Clin Neurosci 12 : 17-20, 2005 